\title{
Research on the Innovation of Freehand Sketching Teaching Method of Landscape Design Based on New Media
}

\author{
Huang Liang \\ Department of Art Design, Chongqing Aerospace Polytechnic, 400021
}

Keywords: New Media; Landscape Design; Teaching; Innovation

\begin{abstract}
New media, which is no stranger to many people, refers to the new media form that appears under the conditions of informationization. With the characteristics of storing and disseminating information, it has distinct and irreplaceable features and advantages. New media has had a long-term and profound impact on people's work and study. In the field of education, the emergence of new media has provided tremendous opportunities for the transformation of many disciplines. This paper briefly introduces the many characteristics of new media and provides means to innovate freehand sketching teaching methods for landscape design in the new media environment.
\end{abstract}

The term new media can often be seen in the media in recent years, and many people are no longer unfamiliar with this term. But it's not easy to really clarify the definition of new media. The so-called new media, in a certain sense, refers to the environment in which all things are media. In short, new media more refers to an environment and it covers almost all digital media formats, including traditional networks, online media, mobile media, digital TV newspapers and so on. With rich contents, the new media is a broader concept. As far as the application of new media is concerned, it mainly refers to the use of digital technology, network technology. Through the Internet and terminal devices such as computers, mobile phones, digital TV terminals, etc., it provides information and entertainment services for specific users. Therefore, many people also refer to new media as digital new media.

The new media is interactive and timely, and it can spread a massive amount of information in a variety of forms between individuals and communities. With the development of science and technology and the progress of the times, new media has received increasing attention from all walks of life. The continuous prosperity of new media has also aroused widespread concern in the academic world that many scholars have conducted long-term systematic research on the application of new media in education and teaching and made many bold attempts. Overall, very promising results have been achieved, and new media has become a powerful aid in education and teaching.

\section{The Characteristics of New Media and its Impact on Traditional Education}

New media has many advantages that traditional media can’t match. First of all, new media has 
novel forms and distinct images. New media is a three-dimensional information dissemination carrier and means of communication that combines a variety of performances such as sound, video, and text. In the process of communication, it displays the rigid text content in a novel and vivid form to the audience through colors, light and shadow, and text interaction. Secondly, the new media can store a wealth of information and display the information in a centralized way. Finally, compared with traditional media, new media is much interactive, which enables new media not only to passively display content but also to achieve peer-to-peer communication and interaction between multiple parties.

With these characteristics and advantages, new media have broad application prospects in education and teaching. With the rapid development of new media technologies and the advancement of technology, new media has been widely used at many schools for education and teaching, posing a strong challenge to traditional education and teaching in many aspects. Landscape design freehand sketching is particularly strongly affected as a highly practical course. The new media technology is conducive to transforming the traditional education concept of landscape design freehand sketching, promoting the change of freehand sketching teaching mode, teaching system, teaching content and teaching methods. With the popularity of new media technology in and out of class, the freehand sketching education and teaching methods of landscape design can be continuously improved, which can greatly benefit the implementation of quality education, reducing the burden and stress on students and stimulating students' interest in learning. All in all, the impact of new media on traditional landscape design freehand sketching can be summarized as follows:

\subsection{Promote the transformation of freehand sketching teaching methods in traditional landscape design}

In the new media environment, students' initiative can be fully guaranteed. In the new media environment, students are able to participate in cooperative learning. The new media uses a networked platform as a learning tool. On this platform, there are rich learning resources, and students can make full use of the network to collect and organize learning materials. This model breaks the traditional teacher-centered approach to education and teaching and highlights students' dominant position. At the same time, new media technologies can also help teachers to update their ideas. Nowadays, with the rapid development of science and technology, teachers shoulder a special historical mission to cultivate students' innovative spirit. Thus, teachers themselves must be good at innovation. If teachers lack innovative thinking, then the discipline will lose its soul and motivation. The application of new media technology in education and teaching includes many cutting-edge scientific and technological achievements. To some extent, the landscape design freehand sketching course in the new media environment is a new concept course. Based on information technology and network technology, it has extended to various fields such as communication and multimedia. In order to fully adapt to the teaching under the new media, teachers must integrate and improve their knowledge structure and broaden their horizons, which is a process of self-improvement and self-remodeling for freehand sketching teachers in the landscape design, and it is also a process to improve teachers' self-innovation ability. This will deeply influence landscape design freehand sketching teachers' understanding of teaching the freehand landscape sketching course at the ideological level. Thus, it is both an extension of ideological understanding and an experience of practical action.

\subsection{Optimize classroom efficiency and improve teaching quality}

The application of new media can effectively improve effect of using teaching methods to 
display complex knowledge in teaching and make it interactive, resulting in explosive growth of teaching content and teaching capacity. In the new media environment, freehand sketching teachers of landscape design at college can produce high-quality courseware with rich contents, various forms and close to students' preferences through modern technology. The communication between students and teachers is no longer limited to time and space, and communication can be carried out anytime and anywhere. Teachers don't have to use chalk or blackboard for teaching like in the past, but they can use tools such as computers, projectors, and network terminals to display pictures, texts, sounds, images and other information from time to time. The freehand sketching course for college landscape design in the new media environment has undergone tremendous changes in terms of information transfer structure, students' understanding structure, integration of time at class, and teacher-student communication methods. Rich and interesting teaching methods and contents have greatly stimulated students' interest in learning and led students to explore unknown areas. In the new media environment, knowledge is no longer a boring symbol but has become a living individual. It stimulates students' cognition and understanding of landscape design freehand sketching, which can effectively improve students' learning efficiency and memory, thus fully optimizing the efficiency and improving the quality of teaching.

\subsection{Improve teaching services and expand teaching space}

At present, on-campus network facilities have basically established at colleges and universities in China. We should make full use of this resource to build a new media curriculum system with the characteristics of school features and freehand sketching. At the school level, the enthusiasm of the freehand sketching teachers and students should be fully mobilized. Teachers should be encouraged to work together to formulate new media curriculum programs in line with professional development planning. And teachers for college landscape design should be mobilized to collect, organize and produce educational resources related to freehand sketching, and a freehand sketching education and teaching database should be established for college landscape design. At the same time, students can be mobilized to manage the collected learning materials in different categories. Teachers will store their own courseware and other resources at a specific address. These resources can include audio resources, video resources, images and text, and so on. The school can motivate teachers of science and engineering related majors to develop simple and easy-to-use clients according to the actual needs of students, so that students can log in the information system at any time in their spare time and quickly and efficiently obtain information and materials. At the same time, interactive software and message boards under the new media can provide channels for communication between teachers and students. In the new media environment, teaching and learning have broken the limitations of time and space, greatly expanding the space for education and teaching and providing a practical guarantee for improving teaching services.

\subsection{Effectively improve students’ practical ability}

The new media originates from traditional media and is better than traditional media. It is the product that combines media and technology. New media is constantly evolving. With the integration of technologies such as the Internet, mobile Internet, and TV networks, we have new channels and means for the cognition and practical ability of things. Compared with the traditional freehand sketching model of landscape design at college, the most essential feature of freehand sketching education in university landscape design is the interactivity. More and more college landscape design freehand sketching classroom teaching has been built based on this. Interactivity makes it possible for students to specialize in personalized landscape design for freehand sketching. Thus, the traditional teaching method with teachers taking the dominant position can be changed, 
and students can change from passively learning to initiatively exploring, and in the exploration of knowledge, students' practical ability can be improved unconsciously. Obviously, this seemingly free education and teaching method can better play students' initiative, creativity and enthusiasm, laying a solid foundation for improving students' practical ability and cultivating their innovative ability.

\section{Innovation of Freehand Sketching Teaching Methods for College Landscape Design in the New Media Era}

The new media environment provides a broad space and convenient way for the innovation and transformation of landscape design freehand sketching. New media is built on digital technology and network technology and can provide all-round services at any time, which not only satisfies the needs of teachers and students for work and study, but also caters to the needs of teaching reform and innovation in the field of education. According to the goal of freehand sketching teaching innovation and reform at colleges and universities in the new era, we should abandon the traditional method of freehand sketching teaching and adopt open landscape design freehand sketching teaching mode at a more profound level and in a wider field. With the general requirements of quality-oriented education, we must adhere to the people-oriented education concept, highlight students' dominant status, use the broad resources of the new media to combine task-driven teaching, and arrange students' learning tasks in and out of class in a scientific, reasonable and orderly manner. It is necessary to explore the potential of students through various channels, stimulate students' enthusiasm and initiative in learning, and continuously cultivate students' self-learning ability so as to cultivate their good habits for future work and life out of campus. Our freehand sketching teaching of college landscape design should not only undertake the basic tasks of college teaching but is also obligate to shape people in terms of personality and conduct. This will enable students to have good thinking, high cultural quality and a strong sense of social responsibility and mission. The freehand sketching teaching of landscape design under the new media is a three-dimensional education method, which can adapt to the needs of educational transformation. In the new media era, the innovation of freehand sketching teaching methods for university landscape design should focus on the following aspects:

\subsection{Optimize and enrich the content of classroom teaching}

In the new media teaching environment, with the introduction of interactive devices, teachers have the conditions to provide students with more teaching and learning resources. The application of audio data, image data, etc. can make classroom teaching no longer boring. Under the new media environment, students' interest in learning is fully stimulated, and the content of teaching changes from a flattened pattern to a three-dimensional and diversified pattern. For example, in the classroom teaching, after playing a freehand sketching video, students can discuss the content of the video in a targeted manner and communicate with the teacher in the interactive terminal timely. Teachers can organize discussions on certain issues. If teachers encounter topics that most students are more concerned about, they can motivate students to use the resources in the new media environment to find answers.

\subsection{Expand the teaching space outside the classroom}

In the traditional freehand sketching study of college landscape design, students are very vulnerable to the constraints of time, space and other environments. The new media teaching supported by network technology is not limited by the time and space, so that teachers and students 
can engage in flexible and convenient classroom interaction at any time and at any place without leaving home. In this way, students can make full use of their spare time. For example, the very popular micro-course is a very successful case of teaching space expansion in the new media environment. At the same time, the application of new media teaching methods can make teachers effectively overcome the differences in learning ability caused by individual differences among students. In the freehand sketching teaching of landscape design in traditional universities, individual differences of students are often ignored, and teachers pursue the standardization and consistence of knowledge imparting based on teaching. For this reason, our education is often based on the premise and result of stifling the personality and freedom of students. It is difficult to teach students in accordance with their aptitude. New media technology makes the people-oriented teaching concept possible, and students can explore learning resources independently according to their own learning hobbies and interests.

\subsection{Improve students’ practical ability}

Landscape design freehand sketching is a very practical course. Without the practical attributes, it loses the basic learning conditions. The after-school exercises in traditional teaching can hardly enhance students' ability to practice freehand sketching. In addition, under the traditional education model, the practice of freehand sketching for students' landscape design is very simple, and many students are quite tired of it. The new media has provided a vast space for the development of students' practical activities and is deeply loved by students. At the same time, students can also exercise their teamwork and innovation skills in these activities.

\section{Conclusion}

The modern education and teaching mode based on new media is the general trend of the future development of higher education. The wide application of new media technology will certainly promote the modernization of freehand sketching teaching in university landscape design. The application of new media technology in the freehand sketching teaching of college landscape design can effectively improve students' comprehensive ability and comprehensive quality, broaden students' professional vision and strengthen students' practical ability. New media plays an important role in improving the efficiency of freehand sketching classroom teaching in college landscape design.

\section{References}

[1] Ren Quanwei. On the Relationship between Freehand Sketching and Garden Landscape Design Teaching [J]. Art Grand View, 2013, (8):144

[2] Wang Yong. The Role and Influence of Freehand Sketching in Environmental Landscape Design[J].Urban Construction Theory Research (Electronic Edition), 2013, (23)

[3] Huang Yu, Lin Wei, Yang Wei, et al. Discussion on the Working Method based on the Combination of SkectchUp and Freehand Sketching[J].Guangdong Garden, 2011, 33(2): 21-24

[4] Ding Jinhua. Analysis on the Teaching Reform of Landscape Planning and Design Course for Landscape Majors[J]. Higher Education of Architecture, 2011(2).

[5] Jia Zhongfeng, Li Chuangang. Exploration on Teaching Practice Reform of Landscape Design Course [J]. Continuing Education Research, 2012(8).

[6] Liang Aili, Chen Shangling. Discussion on Teaching Reform of Landscape Planning and Design Course [J].Guangxi Education· C Edition, 2013(10). 